\title{
Health effects of electromagnetic fields on children
}

\author{
Jin-Hwa Moon, MD, PhD \\ Department of Pediatrics, Hanyang University School of Medicine, Seoul, Korea
}

In today's world, most children are exposed to various man made electromagnetic fields (EMFs). EMFs are electromagnetic waves less than $300 \mathrm{GHz}$. A developing child's brain is vulnerable to electromagnetic radiation; thus, their caregivers' concerns about the health effects of EMFs are increasing. EMF exposure is divided into 2 categories: extremely low frequencies (ELFs; 3-3,000 Hz), involving high-voltage transmission lines and in-house wiring; and radiofrequencies (RFs; $30 \mathrm{kHz}$ to 300 $\mathrm{GHz}$ ), involving mobile phones, smart devices, base stations, WiFi, and 5G technologies. The biological effects of EMFs on humans include stimulation, thermal, and nonthermal, the latter of which is the least known. Among the various health issues related to EMFs, the most important issue is human carcinogenicity. According to the International Agency for Research on Cancer's (IARC's) evaluation of carcinogenic risks to humans, ELFs and RFs were evaluated as possible human carcinogens (Group 2B). However, the World Health Organization's (WHO's) view of EMFs remains undetermined. This article reviews the current knowledge of EMF exposure on humans, specifically children. EMF exposure sources, biological effects, current WHO and IARC opinions on carcinogenicity, and effects of EMF exposures on children will be discussed. As well-controlled EMF experiments in children are nearly impossible, scientific knowledge should be interpreted objectively. Precautionary approaches are recommended for children until the potential health effects of EMF are confirmed.

Key words: Electromagnetic field, Extremely low frequency, Radiofrequency, Smart device, Child

\section{Key message}

- The nervous systems of children are more vulnerable to the effects of electromagnetic waves than adults.

- The exposure to electromagnetic fields (EMFs) among children should be minimized.

- According to International Agency for Research on Cancer EMFs are possibly carcinogenic, it should not be overlooked or interpreted with bias.

\section{Introduction}

Electromagnetic radiation is generated from natural environments such as the solar energy and geomagnetic field or from manmade sources. With scientific and technological advancements, our everyday environments are filled with various manmade electromagnetic fields (EMFs). EMFs are invisible and generated from electrical lines, transmission towers, telecommunications, home appliances, mobile phones, $\mathrm{WiFi}$, and base stations. An increasing number of children use computers and iPads for school, entertainment, and social activities. Even infants can be exposed to EMFs in the residential environment or by the direct use of electronic devices (Fig. 1).

There are 2 main categories of EMFs: extremely low frequency $(\mathrm{ELF})$ and radiofrequency (RF) waves. ${ }^{1-3)}$ ELFs can be generated from electrical lines or transmission towers, issues of which have been investigated for the last several decades. RFs can be generated from mobile phones and smart devices and the recent 5th-generation (5G) technologies. The human effects of RFs are less evident and more difficult to study than those of ELFs.

In Korea, general measures have been recommended to reduce EMF exposure such as reducing the use of electronic devices or using them away from the body. However, little is known about the exact amount of daily EMF exposure that can affect a child's health and whether the effects of EMF exposure are similar to those of adults. The developing nervous system is more conductive and absorbs more electromagnetic energies than those of adults. ${ }^{4)}$ Therefore, different standards are required to protect children.

In recent years, pediatricians have become increasingly asked about children's use of electromagnetic devices and the risks of EMF exposure. Thus, more knowledge about pediatric exposure to electromagnetic radiation is required than any other time before. Thus, this article reviews the current knowledge about the health effects of EMF exposure on children. The World Health Organization's (WHO's) opinions and other scientific researches will be critically reviewed, and the precautionary principle to reduce the negative effects of EMF on children will be emphasized.

Corresponding author: Jin-Hwa Moon, MD, PhD. Department of Pediatrics, Pediatric Neurology, Hanyang University Guri Hospital, Gyeongchun-ro 153, Guri 11923, Korea 凶E-mail: jinhwamoon@hanyang.ac.kr, https://orcid.org/0000-0003-0235-5318

Received: 1 December, 2019, Revised: 4 May, 2020, Accepted: 7 May, 2020

This is an open-access article distributed under the terms of the Creative Commons Attribution Non-Commercial License (http://creativecommons.org/licenses/bync/4.0/) which permits unrestricted non-commercial use, distribution, and reproduction in any medium, provided the original work is properly cited.

Copyright (c) 2020 by The Korean Pediatric Society 


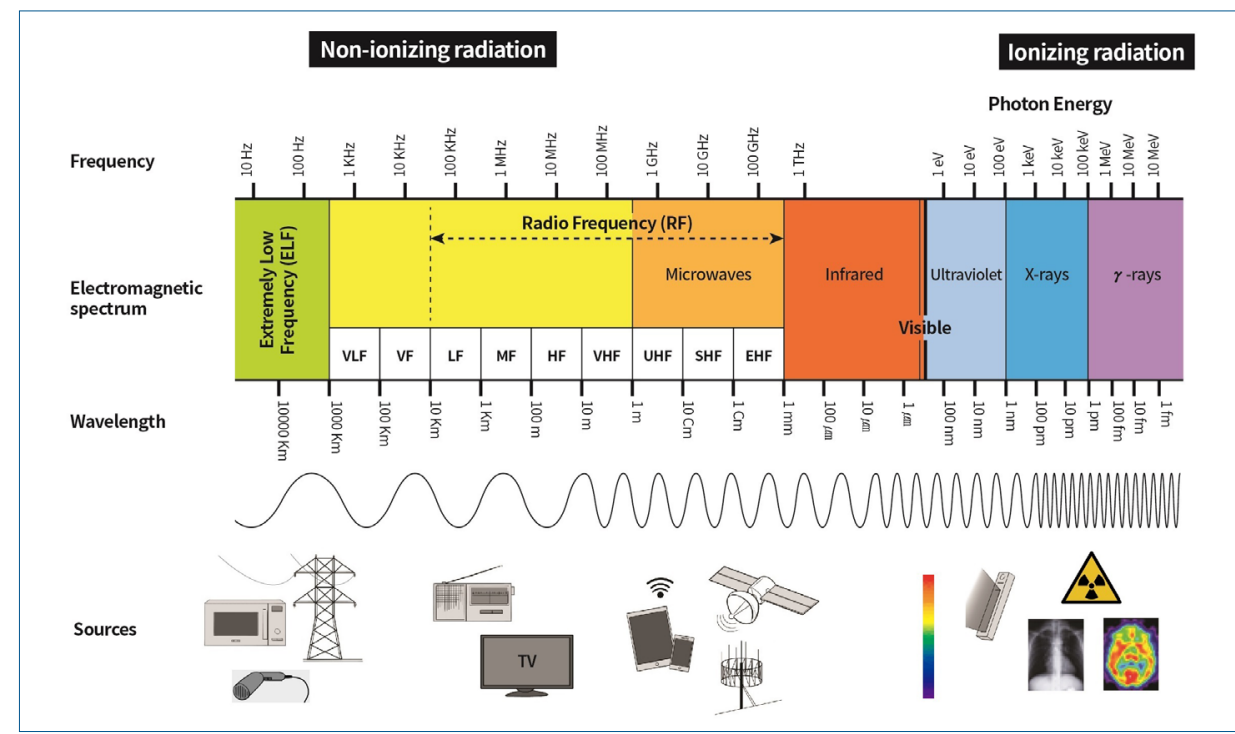

Fig. 1. The electromagnetic spectrum. Frequencies (expressed by hertz, $\mathrm{Hz}$ ) increase from left to right, while wavelengths decrease from right to left. lonizing radiations are $x$-rays and $y$-rays. EHF, extremely high frequency; HF, high frequency; LF, low frequency; MF, medium frequency; SHF, super-high frequency; VF, voice frequency; $V H F$, very high frequency; $V L F$, very low frequency; UHF, ultra-high frequency.

\section{Sources of EMF exposure}

Whenever electrical current flows, both electrical and magnetic fields are generated, known as EMFs. Electric field strength is measured as volts per meter $(\mathrm{V} / \mathrm{m})$, while magnetic field strength is measured as amperes per meter $(\mathrm{A} / \mathrm{m})$. A magnetic field can be measured as magnetic flux density (Tesla).

The electromagnetic spectrum is categorized into a frequency range: ELF, RF, infrared, visible, ultraviolet, and ionizing radiations ( $\mathrm{x}$ - and $\gamma$-radiation). ${ }^{1,3)}$ EMF refers to waves less than $300 \mathrm{GHz}$, which includes most of the frequencies in everyday exposure. The lowest frequencies $(3-3,000 \mathrm{~Hz})$ are referred to as ELF-EMF, while the higher frequencies $(30 \mathrm{kHz}$ to $300 \mathrm{GHz}$, under infrared) are referred to as RF-EMF (Fig. 2).

\section{Extremely low-frequency EMFs}

ELF-EMFs are generated from electricity, electrical machines, transmission towers, and high-voltage lines. In Korea, electric power is operated at $60 \mathrm{~Hz}$. More EMFs are absorbed with the use of appliances that are close to the body (e.g., hair dryers, bidets, massagers, and electric blankets). The general recommendation is that electrical appliances should be used at least 30 cm away from the body (http://www.emf.or.kr/general/html/life/ guideline.pdf).

\section{Radiofrequency EMFs}

RF-EMFs are generated from mobile phones, smart devices, WiFi, base stations, and radars. Radio or television transmitters and base stations can be large sources of RF exposure. Mobile phones generate more electromagnetic waves when used in a fast-moving subway or train or when searching for a base station before the ring back tone. ${ }^{5)}$

\section{Biological effects of EMFs}

The main effects of EMFs on the human body are stimulation, thermal, and nonthermal. Stimulation effects involve the nerves and muscles at a high EMF, can be used for medical devices, and can cause electrical shock at very high stimulation levels. Thermal effects involve an increase in body temperature. Hot senses of the ear or body during mobile phone or laptop use are some examples. Nonthermal effects result from recurrent long-term exposure and may be related to the so-called electromagnetic hypersensitivity syndrome or neurodevelopmental disorders. However, the nonthermal effect is the least well investigated. ${ }^{6}$

The effects of EMF exposure differ with respect to frequencies and strength. For frequencies less than $300 \mathrm{GHz}$, limitation levels for human protection have been well established for public and occupational workers. ${ }^{78}$ From $100 \mathrm{kHz}$ to $10 \mathrm{GHz}$, which includes the use of mobile phones, limitation level is expressed as a specific absorption rate $(\mathrm{SAR}, \mathrm{W} / \mathrm{kg}){ }^{2,8)}$

One of the major issues of EMF involves human carcinogenesis. Since the first report on residential ELF-EMF and childhood leukemia in 1979, several studies have investigated this association. ${ }^{1,27}$ However, because of the nature of electromag. netic radiation, most studies were based on epidemiological data or animal experiments.

Animal studies on prenatal RF exposure demonstrated the deleterious effects of RF-EMF on the brain. Prenatal exposure to $900 \mathrm{MHz}$ resulted in substantial loss of granule cells ${ }^{9)}$ or a significant reduction in pyramidal neurons. ${ }^{10)}$ Mice exposed to in utero RF from cellular telephones were hyperactive and demonstrated memory impairment after birth. ${ }^{11)}$ EMFs from mobile phones changed the blood-brain barrier's permeability and damaged neurons in the brains of exposed rats. ${ }^{12-14)}$

Brain oxidative stress and epigenetics are considered biological 


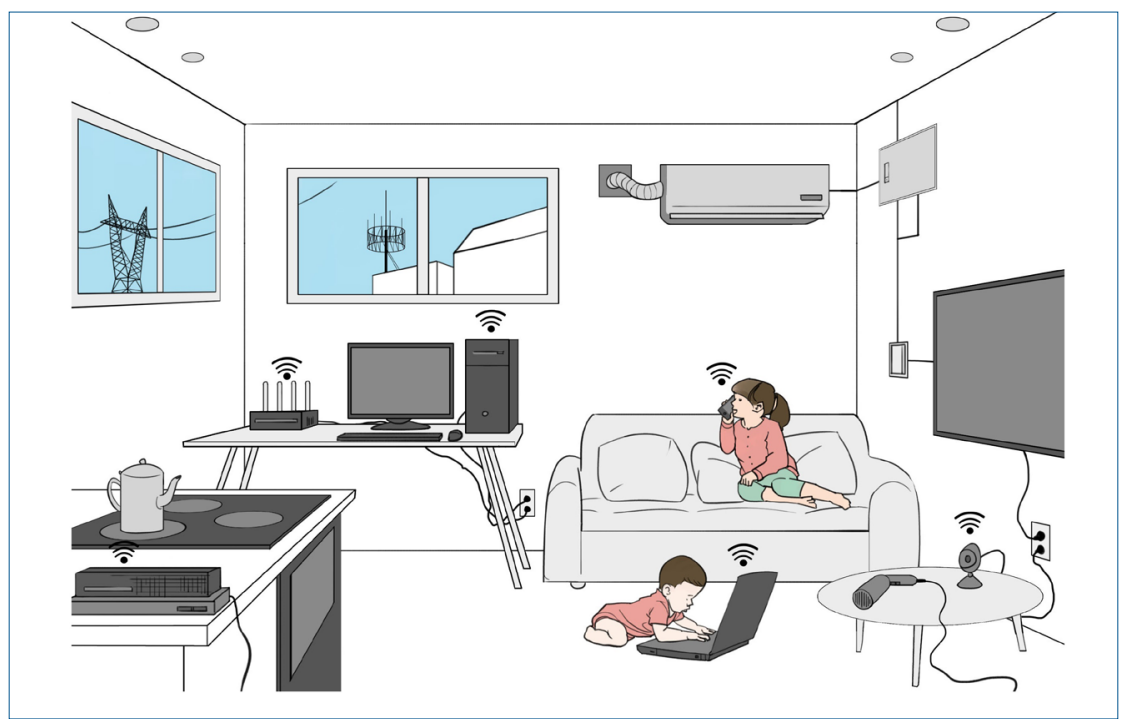

Fig. 2. Various sources of electromagnetic fields (EMFs). Extremely low-frequency EMFs are generated by electricity, various home appliances, in-house wiring, and outside high-voltage lines. Radio frequency EMFs waves are generated by mobile phones, smart devices, WiFi, base stations, and other devices.

mechanisms of RF-EMF effects. Several theories suggest that EMF exposure results in oxidative stress and reactive oxygen species and loss of cells and blocks their production. ${ }^{15)}$ Oxidative stress parameters increase lipid hydroperoxide and myelo. peroxidase activity in immature rats. ${ }^{16}$ RF-EMF exposure may change deoxyribonucleic acid methylation, histone modification, chromatin remodeling, and microribonucleic acid. ${ }^{16-18)}$ However, the results of studies on brain oxidative stress induced by EMF are inconsistent.

In Korea, many websites for public and nonpublic institutions provide information aiming to improve public awareness and EMF knowledge. ${ }^{19-22)}$ This information includes large amounts of data on human limitation levels, EMF measurements of electronic products, base station information, general safety guidelines, and false beliefs. Although the websites provide general information for public awareness, they sometimes conclude that the public concerns regarding carcinogenicity and nonthermal effects are exaggerated and have insufficient evidence. However, such conclusions may be hasty. Because evidence of the relevant websites is often based on WHO fact sheets, it is necessary for clinicians to review the $\mathrm{WHO}$ opinion and evaluate other scientific evidence objectively.

On the other hand, some individual websites or personal blogs deliver scientifically unreasonable negative information to users. Such messages exaggerate claims and interfere with reasonable discussions about EMF health effects.

\section{Different tones for human carcinogenicity}

\section{Carcinogenicity of ELF-EMF}

In 1996, the WHO organized an international EMF project task group to investigate the potential health risks of EMFassociated technologies. In the resulting fact sheet in 2007, the
WHO concluded that there were no substantive health issues related to ELF electric fields at levels generally encountered by the public.7) This position was based on findings and reviews of the WHO task group as well as the International Agency for Research on Cancer (IARC, 2002) and International Commission on Non-Ionizing Radiation Protection (2003). ${ }^{2,7,23)}$ The WHO task group referenced the IARC monograph evaluating the carcinogenic risks in humans in 2002 that classified ELF as a possible carcinogen. ${ }^{2)}$ However, the task group commented that the epidemiological evidence of carcinogenicity was weakened by methodological problems such as potential selection bias.")

In fact, the IARC's 2002 monograph evaluated a number of scientific studies on ELF electronic and magnetic fields and childhood and adult cancers. ${ }^{2)}$ In the part about the effects on children, it stated that "pooled analyses showed 2-fold excess risk for exposure to ELF magnetic fields above $0.4 \mu \mathrm{T}$ and a relative risk of 1.7 for exposure above $0.3 \mu \mathrm{T} .{ }^{\prime \prime}{ }^{2)}$ The IARC concluded that ELF magnetic fields were possibly carcinogenic to humans (Group 2B) and that the association between child leukemia and a high magnetic field was unlikely to be due to chance. ${ }^{2)}$ In contrast to ELF magnetic fields, evidence on the association between ELF electric fields and leukemia was inadequate, and the associations between other childhood brain tumors or cancers and ELF were inconsistent. ${ }^{2)}$

The IARC is a working group under the auspices of WHO. Despite this, the different views between the WHO and the IARC may have originated from the differences in their respective members. Many committee members of the WHO's EMF project were involved with electricity-associated industries, whereas the IARC membership included more epidemiologists and health specialists. ${ }^{24)}$ In Korea, several public websites on EMF safety frequently cite the WHO EMF opinion. Some citations seem to have been changed through self-citation, which may cause the misleading interpretation that there is no scientific 
evidence of carcinogenicity.

\section{Carcinogenicity of RF-EMF}

A large international case-control study (INTERPHONE study, 2000) that aimed to determine the association between adult brain tumor risk and mobile telephone use reported no overall increase in brain tumor risk with the use of mobile phones. ${ }^{25)}$ However, in the 10th highest decile of cumulative call time ( $\geq 1,640$ hours), the odd ratios were 1.4 for glioma and 1.15 for meningioma. ${ }^{25)}$ Glioma tended to occur more commonly in the temporal lobe on the side of usual phone use. ${ }^{25}$ ) After the INTERPHONE study, in 2013, the IARC published another monograph evaluating the carcinogenic risks of RFEMF on humans. ${ }^{3)}$ Similar to ELF magnetic fields, the IARC classified RF-EMFs as "possibly carcinogenic to humans (Group 2B)."3)

In 2014, the WHO also published the following fact sheet on mobile phone EMF and public health. ${ }^{26)}$ Similar to ELF, the WHO opinion was undetermined. It referenced the IARC's classification of mobile phone use as possibly carcinogenic to humans. However, the WHO group repeated the comment that the "biases and errors limit the strength of these conclusions and prevent a causal interpretation." ${ }^{26)}$ Such undetermined views of the WHO on the adverse effects of RF or ELF-EMF have been criticized by several scientist groups, which have requested that the WHO should reevaluate all health effects of EMF and include experts from all related fields such as health, medicine, and engineering to reassess the effects of EMFs. ${ }^{24,27,28)}$

\section{Other EMF effects on children's health}

In everyday life, children are exposed to indoor and outdoor EMFs. Although well-designed case-control studies are lacking, we can consider the available data in hypothesizing about the effects of EMF on children.

\section{ELF effects on and children}

ELF from high-voltage power lines can affect children living near them; in fact, children can be continuously affected by low-level in-house wiring. Much of the results regarding ELF and children's health are based on epidemiologic studies with childhood leukemia as described in the previous section.

While conducting the international EMF project, the WHO conducted an international workshop on "Sensitivity of children to EMF exposure" (Istanbul, Turkey, June 2004) of both ELF and RF-EMF exposure. They concluded that there was no direct evidence that children were more vulnerable to EMF because very few studies assessed this topic. ${ }^{29)}$ However, considering the uncertain effects of EMF on children, the WHO recommended general measures such as reducing personal EMF exposure. They also recommended minimizing EMF exposure in schools, kindergartens, and any locations where children remain for a substantial part of the day. ${ }^{1,29)}$

\section{RF effects on children}

Whether children are vulnerable to RF has been debated for the last 20 years, when children were widely exposed to mobile phones. Human and animal model studies yielded significant findings regarding cellular phone use: increased headache, sleep disruption, neurotransmitter release, synaptic plasticity alterations, and neuronal cell cycles. ${ }^{30-34)}$ However, the experimental environment and RF doses may differ from those of actual exposures.

The Korean study conducted in 1993-1999 involving 1,928 children with leukemia and 956 children with brain tumors. It revealed that the risk of leukemia was 2.15 times higher in the group living within $2 \mathrm{~km}$ from AM radio transmitters than in the group living more than $20 \mathrm{~km}$ from it. ${ }^{35)}$

In 2000, the "Stewart report" by the UK Independent Expert Group on Mobile Phones declared that children may be more vulnerable to EMF than any other age groups. ${ }^{4,36)}$ They stated that "children are exposed to electromagnetic waves over a longer life time than adults and their nervous systems are in the process of development. As the conductivity of the children is higher due to higher moisture and ionic content than adults, and more than adults, children's head absorbs a lot of RF energy" (Fig 3). ${ }^{4)}$ Stewart's report suggested that children should not be encouraged to use mobile phones unnecessarily and that mobile phone companies should not promote their use in children. ${ }^{4)}$ Since Stewart's report, debate regarding the vulnerability of a child's brain surfaced from the Netherlands and Russia. ${ }^{37,38)}$

\section{Studies of mobile phone RF exposure in children}

The skull thickness of adults is approximately $2 \mathrm{~mm}$. However, the skull thickness of a 5-year-old child is approximately $0.5 \mathrm{~mm}$ and $1 \mathrm{~mm}$ in 10 years. ${ }^{39)}$ Therefore, radiation penetration is larger in children than in adults. ${ }^{39,40)}$ As a child's head diameter is smaller, the energy-absorbing "hot spots," the most sensitive parts of RF, are more pronounced. ${ }^{41)}$ Several engineering strateg. ies to avoid the hazard of RF do not consider a child's head

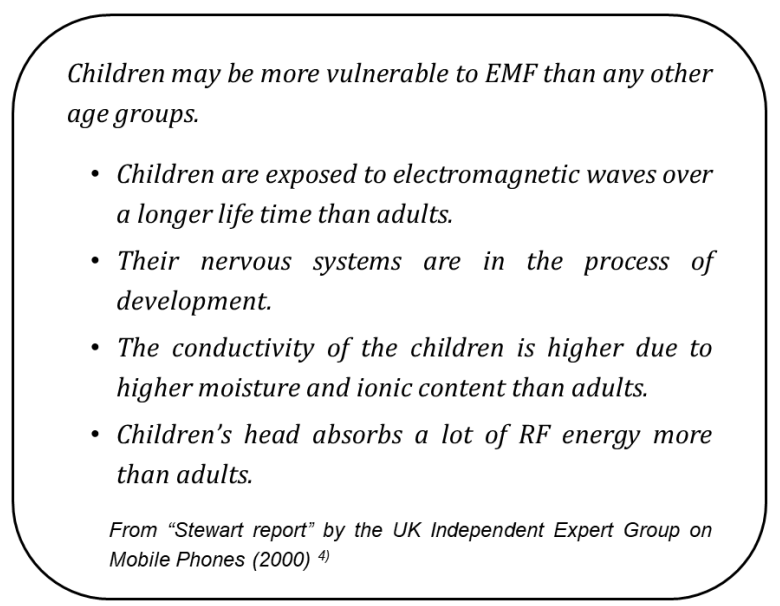

Fig. 3. The vulnerability of children to electromagnetic field exposure according to the UK Independent Expert Group on Mobile Phones. EMF, electromagnetic field; RF, radiofrequency. 
specificity.

The results of the study that assessed the associations between RF exposure and cell phone use, residential RF-EMF levels, and cognitive function tests were inconsistent. ${ }^{42-46)}$ Ten-yearold children living in areas with higher RF exposure did not show any effects in most of the cognitive parameters; however, they did show lower verbal scores and higher internalizing and total problems. ${ }^{46}$ In a study of children aged 5-6 years, greater residential RF exposure from base stations and the presence of indoor sources were associated with improved inhibitory control and flexibility of cognition but also reduced visuomotor coordination. $^{47)}$

The associations between RF exposure and mobile phone use and sleep in children are inconsistent. ${ }^{48-50)}$ Habitual and frequent use of mobile phones was associated with lower sleep quality, while higher tablet use was associated with decreased sleep efficiency. ${ }^{49)}$ Arousal and blue light may underlie these problems. Residential exposure to RF-EMF from base stations was not associated with sleep onset delay, night awakening, parasomnia, and daytime sleepiness in 7-year-old children; however, higher mobile phone use was associated with less favorable sleep duration, night awakening, and parasomnia. ${ }^{50)}$

Cell phone use by pregnant mothers during the pre- and postnatal periods can contribute to behavioral problems in children. ${ }^{51)}$ In children exposed to cell phones during the pre- and postnatal periods, the odds ratio for behavioral problems was 1.8 after the adjustment of potential confounders. ${ }^{52}$

Recently, the European Union-funded international study evaluating the association between RF exposure by mobile phones and brain tumor risk in children and adolescents (MOBIKIDS) was conducted. ${ }^{53)}$ This large study included nearly 900 eligible patients from 14 countries, including Korea, and the final results are still pending. ${ }^{54)}$

The 5G technologies using electromagnetic waves can make hyper-connected network environments capable of augmented reality and 3-dimensional service. The $5 \mathrm{G}$ frequency comprises 3.5-GHz and 28-GHz bands. The effect of the 3.5-GHz band on humans may be similar to that of $4 \mathrm{G}$ and can utilize the existing base station, but $28 \mathrm{GHz}$ may be different to the human body and the base stations must be installed more closely. Therefore, the long term effects of $5 \mathrm{G}$ on children's health are unestablished. The impact of $5 \mathrm{G}$ technologies on children has never been evaluated. ${ }^{55)}$

\section{Precautionary principles for children}

International policies and advisory responses regarding children's exposure to RF-EMF vary. RF-EMF-related advisory policies for children are as follows: banning mobile phone advertising or sale to children, SAR labeling, and preferring wired connection to WiFi in schools. In Korea, only the policy of SAR labeling on mobile phone is strictly followed. Similar to other scientific uncertainties, precautionary principles should be followed for the EMF problem (EC, 2017). ${ }^{56}$ The meaning of precautionary principle is as follows: when human activities may
Table 1. Precautions to reduce the risk of excessive electromagnetic field (EMF) exposure in children

Children can be exposed to EMF by electronic devices, high-voltage transmission lines, mobile phones, WiFi, etc.

For parents:

Avoid long-term exposure to strong EMFs in home, school, or other places children spend much of their time.

Avoid using electrical devices within $30 \mathrm{~cm}$ of the body.

- Avoid using smartphones directly against your child's head.

- Keep your child's body from getting hot while using mobile phones.

Do not allow your child to use smart devices during meals or for the last hour before bed.

Note that the effects of various devices using virtual reality and WiFi have on the neural development of children remain unknown.

- Most products that claim to reduce EMFs are ineffective or unproven.

- Ask your child's pediatrician for information to guide your child's use of smart devices.

For teachers, policymakers, and commercial companies:

- Teachers: Educate children on how to avoid excessive EMF exposure.

- Policymakers: Create policies to reduce children's EMF exposure from the environment.

Commercial companies: Create products that reduce children's exposure to EMFs and issue warnings about them.

EMFs, electromagnetic fields.

lead to morally unacceptable harm that is scientifically plausible but uncertain, actions shall be taken to avoid or diminish that harm (UNESCO 2015). For children, strict standards are required until scientific knowledge is established, specifically in facilities such as schools and preschools, where they stay longer. This article suggests precautions to reduce the risk of excessive EMF exposure in children (Table 1).

\section{Conclusion}

The nervous systems of children are more vulnerable to the effects of electromagnetic waves than those of adults. Although studies on the effects of EMFs on children's health are unestablished, precautionary principles should be followed for children and the exposure to EMFs among children should be minimized. The fact that EMFs are possibly carcinogenic according to the IARC should not be overlooked or interpreted with bias, and the opinions of clinicians should be given more weight than those of industries in the establishment of safety policies for EMF use. Moreover, a study that assesses the effects of $5 \mathrm{G}$ frequency technology on children's health is required.

\section{Conflicts of interest}

The author declares no conflicts of interest.

\section{Acknowledgments}

This work was supported by the National Research Foundation of Korea (NRF2019R1F1A1058704) and research fund of Hanyang University (HY-2016). 


\section{References}

1. Kheifets L, Repacholi M, Saunders R, van Deventer E. The sensitivity of children to electromagnetic fields. Pediatrics 2005;116:e303-13.

2. IARC Working Group on the Evaluation of Carcinogenic Risks to Humans. Non-ionizing radiation, Part 1: static and extremely low-frequency (ELF) electric and magnetic fields. IARC Monogr Eval Carcinog Risks Hum 2002;80:1-395.

3. IARC Working Group on the Evaluation of Carcinogenic Risks to Humans. Non-ionizing radiation, Part 2: Radiofrequency electromag. netic fields. IARC Monogr Eval Carcinog Risks Hum 2013;102(Pt 2):1460.

4. Stewart W. Mobile phones and health, report of independent expert group on mobile phones. Chilton (UK): IEGMP Secretariat, 2000.

5. National Institute of Environmental Research [Internet]. Incheon (Korea): National Institute of Environmental Research; [cited 2019 Oct 17]. Available from: http://www.nier.go.kr/NIER/cop/bbs/selectNoLoginBoard Article.do.

6. Markov M, Grigoriev Y. Protect children from EMF. Electromagn Biol Med 2015;34:251-6.

7. World Health Organization [Internet]. Electromagnetic fields and public health; exposure to extremely low frequency fields. Geneva (Switzerland): World Health Organization; [updated 2007 Jun; cited 2019 Oct 5]. Available from: https://www.who.int/peh-emf/publications/facts/fs322/en/.

8. Guidelines for limiting exposure to time-varying electric, magnetic, and electromagnetic fields (up to $300 \mathrm{GHz}$ ). International Commission on Non-Ionizing Radiation Protection. Health Phys 1998;74:494-522.

9. Odaci E, Bas O, Kaplan S. Effects of prenatal exposure to a $900 \mathrm{MHz}$ electromagnetic field on the dentate gyrus of rats: a stereological and histopathological study. Brain Res 2008;1238:224-9.

10. Bas O, Odaci E, Kaplan S, Acer N, Ucok K, Colakoglu S. $900 \mathrm{MHz}$ electromagnetic field exposure affects qualitative and quantitative features of hippocampal pyramidal cells in the adult female rat. Brain Res 2009;1265:178-85.

11. Aldad TS, Gan G, Gao XB, Taylor HS. Fetal radiofrequency radiation exposure from 800-1900 mhz-rated cellular telephones affects neurodevelopment and behavior in mice. Sci Rep 2012;2:312.

12. Salford LG, Brun AE, Eberhardt JL, Malmgren L, Persson BR. Nerve cell damage in mammalian brain after exposure to microwaves from GSM mobile phones. Environ Health Perspect 2003;111:881-3.

13. Schirmacher A, Winters S, Fischer S, Goeke J, Galla HJ, Kullnick U, et al. Electromagnetic fields $(1.8 \mathrm{GHz})$ increase the permeability to sucrose of the blood-brain barrier in vitro. Bioelectromagnetics 2000;21:338-45.

14. Nittby H, Brun A, Eberhardt J, Malmgren L, Persson BR, Salford LG. Increased blood-brain barrier permeability in mammalian brain 7 days after exposure to the radiation from a GSM-900 mobile phone. Pathophysiology 2009;16:103-12.

15. Maaroufi K, Save E, Poucet B, Sakly M, Abdelmelek H, Had-Aissouni L. Oxidative stress and prevention of the adaptive response to chronic iron overload in the brain of young adult rats exposed to a 150 kilohertz electromagnetic field. Neuroscience 2011;186:39-47.

16. Kaplan S, Deniz OG, Önger ME, Türkmen AP, Yurt KK, Aydın I, et al. Electromagnetic field and brain development. J Chem Neuroanat 2016; 75(Pt B):52-61.

17. Dasdag S, Akdag MZ, Erdal ME, Erdal N, Ay OI, Ay ME, et al. Effects of $2.4 \mathrm{GHz}$ radiofrequency radiation emitted from $\mathrm{Wi}$-Fi equipment on microRNA expression in brain tissue. Int J Radiat Biol 2015;91:555-61.

18. Gye MC, Park CJ. Effect of electromagnetic field exposure on the reproductive system. Clin Exp Reprod Med 2012;39:1-9.

19. Electromagnetic field (EMF) [Internet]. Seoul (Korea): EMF; c2005 [cited 2019 Oct 5]. Available from: http://www.emf.or.kr/.

20. National Radio Research Agency [Internet]. Naju (Korea): National Radio Research Agency; c2018 [cited 2019 Oct 10]. Available from: https://rra.go.kr/ko/index.do/.

21. Korea Communications Agency [Internet]. Naju (Korea): Korea Communications Agency; c2014 [cited 2019 Oct 10]. Available from: https://emf. kca.kr/.

22. Korea Electric Power Corporation [Internet]. Naju (Korea): Korea Electric Power Corporation; c2019 [cited 2019 Oct 10]. Available from: http://home.kepco.co.kr/kepco/KO/D/A/KODAPP001.do?menuCd= FN050401/.

23. International Commission on Non-Ionizing Radiation Protection. Exposure to static and low frequency electromagnetic fields, biological effects and health consequences $(0-100 \mathrm{kHz})$. Munich (Germany): International Commission on Non-Ionizing Radiation Protection, 2003.

24. Hardell L. World Health Organization, radiofrequency radiation and health - a hard nut to crack (Review). Int J Oncol 2017;51:405-13.

25. INTERPHONE Study Group. Brain tumour risk in relation to mobile telephone use: results of the INTERPHONE international case-control study. Int J Epidemiol 2010;39:675-94.

26. World Health Organization. Electromagnetic fields and public health: mobile phones [Internet]. Geneva (Switzerland): World HealthOrganization; 2014 Oct [cited 2019 Oct 10]. Available from: https://www.who. $\mathrm{int} / \mathrm{en} /$ news-room/fact-sheets/detail/electromagnetic-fields-and-publichealth-mobile-phones.

27. Di Ciaula A. Towards $5 \mathrm{G}$ communication systems: are there health implications? Int J Hyg Environ Health 2018;221:367-75.

28. Russell CL. $5 \mathrm{G}$ wireless telecommunications expansion: public health and environmental implications. Environ Res 2018;165:484-95.

29. Repacholi M, Saunders R, van Deventer E, Kheifets L. Guest editors' introduction: is EMF a potential environmental risk for children? Bioelectromagnetics 2005;Suppl 7:S2-4.

30. Frey AH. Headaches from cellular telephones: are they real and what are the implications? Environ Health Perspect 1998;106:101-3.

31. Hocking B, Westerman R. Neurological effects of radiofrequency radiation. Occup Med (Lond) 2003;53:123-7.

32. Wagner P, Röschke J, Mann K, Hiller W, Frank C. Human sleep under the influence of pulsed radiofrequency electromagnetic fields: a poly. somnographic study using standardized conditions. Bioelectromagnetics 1998;19:199-202.

33. Maskey D, Pradhan J, Aryal B, Lee CM, Choi IY, Park KS, et al. Chronic $835-\mathrm{MHz}$ radiofrequency exposure to mice hippocampus alters the distribution of calbindin and GFAP immunoreactivity. Brain Res 2010; 1346:237-46.

34. Panagopoulos DJ. Chromosome damage in human cells induced by UMTS mobile telephony radiation. Gen Physiol Biophys 2019;38:44554.

35. Ha M, Im H, Lee M, Kim HJ, Kim BC, Gimm YM, et al. Radio-frequency radiation exposure from $\mathrm{AM}$ radio transmitters and childhood leukemia and brain cancer. Am J Epidemiol 2007;166:270-9.

36. Martens L. Electromagnetic safety of children using wireless phones: a literature review. Bioelectromagnetics 2005;Suppl 7:S133-7.

37. van Rongen E, Roubos EW, van Aernsbergen LM, Brussaard G, Havenaar J, Koops FB, et al. Mobile phones and children: is precaution warranted? Bioelectromagnetics 2004;25:142-4.

38. Grigoriev Y. Mobile phones and children: is precaution warranted? Bioelectromagnetics 2004;25:322-3.

39. Warille AA, Onger ME, Turkmen AP, Deniz ÖG, Altun G, Yurt KK, et al. Controversies on electromagnetic field exposure and the nervous systems of children. Histol Histopathol 2016;31:461-8.

40. Wiart J, Hadjem A, Gadi N, Bloch I, Wong MF, Pradier A, et al. Modeling of RF head exposure in children. Bioelectromagnetics 2005;Suppl 7:S1930.

41. Kritikos HN, Schwan HP. Hot spots generated in conducting spheres by electromagnetic waves and biological implications. IEEE Trans Biomed Eng 1972;19:53-8.

42. Abramson MJ, Benke GP, Dimitriadis C, Inyang IO, Sim MR, Wolfe RS, et al. Mobile telephone use is associated with changes in cognitive function in young adolescents. Bioelectromagnetics 2009;30:678-86.

43. Redmayne M. International policy and advisory response regarding children's exposure to radio frequency electromagnetic fields (RF-EMF). Electromagn Biol Med 2016;35:176-85.

44. Thomas S, Heinrich S, von Kries R, Radon K. Exposure to radio- 
frequency electromagnetic fields and behavioural problems in Bavarian children and adolescents. Eur J Epidemiol 2010;25:135-41.

45. Hutter HP, Moshammer H, Wallner P, Kundi M. Subjective symptoms, sleeping problems, and cognitive performance in subjects living near mobile phone base stations. Occup Environ Med 2006;63:307-13.

46. Calvente I, Pérez-Lobato R, Núñez MI, Ramos R, Guxens M, Villalba J, et al. Does exposure to environmental radiofrequency electromagnetic fields cause cognitive and behavioral effects in 10-year-old boys? Bioelectromagnetics 2016;37:25-36.

47. Guxens M, Vermeulen R, van Eijsden M, Beekhuizen J, Vrijkotte TGM, van Strien RT, et al. Outdoor and indoor sources of residential radiofrequency electromagnetic fields, personal cell phone and cordless phone use, and cognitive function in 5-6 years old children. Environ Res 2016;150:364-74.

48. Cain N, Gradisar M. Electronic media use and sleep in school-aged children and adolescents: A review. Sleep Med 2010;11:735-42.

49. Cabré-Riera A, Torrent M, Donaire-Gonzalez D, Vrijheid M, Cardis E, Guxens M. Telecommunication devices use, screen time and sleep in adolescents. Environ Res 2019;171:341-7.

50. Huss A, van Eijsden M, Guxens M, Beekhuizen J, van Strien R, Kromhout $\mathrm{H}$, et al. Environmental radiofrequency electromagnetic fields exposure at home, mobile and cordless phone use, and sleep problems in 7-year-old children. PLoS One 2015;10:e0139869.

51. Divan HA, Kheifets L, Obel C, Olsen J. Cell phone use and behavioural problems in young children. J Epidemiol Community Health 2012;66: 524-9.
52. Divan HA, Kheifets L, Obel C, Olsen J. Prenatal and postnatal exposure to cell phone use and behavioral problems in children. Epidemiology 2008;19:523-9.

53. Sadetzki S, Langer CE, Bruchim R, Kundi M, Merletti F, Vermeulen R, et al. The MOBI-Kids Study Protocol: challenges in assessing childhood and adolescent exposure to electromagnetic fields from wireless telecommunication technologies and possible association with brain tumor risk. Front Public Health 2014;2:124.

54. Final Report Summary - MOBI-KIDS (risk of brain cancer from exposure to radiofrequency fields in childhood and adolescence) [Internet]. CORDIS; 2017 [updated 2017 Jan; cited 2019 Nov 15]. Available from: https://cordis.europa.eu/project/rcn/89894/reporting/en.

55. Choi HD, Kim N. 5 G jeonjapawa inche yeonghyang. In: Proceedings of the Korea Electromagnetic Engineering Society 2018;29:26-30.

56. Science for Environment Policy (2017) The precautionary priniple: decision making under uncertainty. Future Brief 18. Produced for the European Commission DG Environment by the Science Communication Unit, UWE, Bristol [Internet]. [cited 2019 Oct 10]. Available from: http:// ec.europa.eu/science-environment-policy.

How to cite this article: Moon JH. Health effects of electromagnetic fields on children. Clin Exp Pediatr 2020;63:422-8. https://doi.org/10.3345/cep.2019.01494 